\title{
ANTIINFLAMMATORY PROPERTIES OF PEPTIDE COMPLEX OBTAINED FROM THE COD LIVER (GADIDAE) ON THE MODEL OF ADJUVANT ARTHRITIS IN THE RAT
}

\author{
(C) Rybakova A. V. ${ }^{2}$, Kovaleva M. A. ${ }^{1}$, Kryshen K. L. ${ }^{1}$, Avdeeva O. I. ${ }^{1}$, Makarenko I. E. ${ }^{1,}$ \\ Makarova M. N. ${ }^{1}$, Makarov V. G. ${ }^{1}$
}

${ }^{1}$ St-Petersburg Institute of Pharmacy, Russia

${ }^{2}$ The St.-Petersburg state academy of veterinary medicine, Russia

The aim of the study was to evaluate the antiinflammatory activity of newly designed multipeptide complex (PC) obtained from the cod liver (Gadidae). PC is a standardized extract that contains peptides, phospholipids, free amino acids and micro-elements. Animal models of rheumatoid arthritis (RA) are used extensively in study of pathogenesis of inflammation and the testing of potential anti-arthritic agents. One of the widely used models of RA is adjuvant arthritis in the rat. Experiment was performed on 60 female Wistar rats $(180-220 \mathrm{~g})$ and was approved by the local ethical commission. RA was induced by subplantar injection into the right hind paw of $100 \mu \mathrm{l}$ complete Freund adjuvant (CFA, Sigma Aldrich). The pathological signs of RA was developed during the 21 days. Temperature of the paw, leucocytes in the blood were registrated to evaluate the pharmacological activity of the tested medicines. Chondro- and osteoprotective effects were evaluated by X-ray study. The experiment rats were randomly divided into the six groups $(n=10)$ as follows: negative control group (normal rats without any treatment and RA pathology), positive control group (RA and with placebo treatment), RA+Alflutop (RA pathology with $0,1 \mathrm{mg} / \mathrm{kg}$ of anti-inflammatory medicine Alflutop treatment), three groups of RA and PC treatment (RA pathology and PC in doses 0,$1 ; 0,2$ and $0,4 \mathrm{mg} / \mathrm{kg}$ treatment). Drug administration was performed by intramascular injection during 21 days (from the first day of experiment once a day). The results shown that PC in the dose of $0,1 \mathrm{mg} / \mathrm{kg}$ has the extensive anti-exsudative effect. Volume of the affected paw was reduced by $70 \%$ compared with the control group. According X-ray analyse PC has hondro- and osteoprotective effects. Thus, the newly designed multipeptide complex (PC) obtained from the cod liver (Gadidae) have high anti-inflammatory activity and is perspective candidat for the chronic inflammation treatment.

\section{INGREDIENTS AND RAW MATERIALS FOR THE DESIGN OF LOW COST FOODS}

\section{() Mandić Anamarija, Ilić Nebojša, Sakač Marijana, Mastilović Jasna}

Institute of Food Technology, University of Novi Sad, Bulevar cara Lazara 1, 21000 Novi Sad, Serbia, E-mail: marijana.sakac@ fins.uns.ac.rs

Development of appealing, affordable and healthy food products that can prevent common nutritional problems in people at risk of poverty are the specific goals of the European Commission-funded project CHANCE (GA 266331). CHANCE project is focused to exploring low cost technologies and ingredients, such as by-products rich in fibre, protein and/or vitamins. To obtain the high dietary fibre ingredients designed for application in meat products two additives were prepared from sugar beet pulp: non-treated fibre (NTF) and treated fibre (TF), and compared with the commercially available product (CAF). Apart from the functionality arising from the high dietary fibre content of the obtained additives, functionality related to the antioxidant activity has been shown to

Table 1. Total phenolic and ferulic acid content in extractable and nonextractable fractions $(\mathrm{mg} / 100 \mathrm{~g}),(\mathrm{M} \pm \mathrm{m})$

\begin{tabular}{|l|c|c|c|}
\hline & CAF & TF & NTR \\
\hline Total phenolics in extractable fraction & $21.9 \pm 0.7^{\mathrm{a}}$ & $8.4 \pm 0.5^{\mathrm{a}}$ & $27.2 \pm 0.9^{\mathrm{a}}$ \\
\hline Total phenolics in nonextractable fraction & $391 \pm 59^{\mathrm{c}}$ & $109 \pm 3^{\mathrm{b}}$ & $265 \pm 50^{\mathrm{d}}$ \\
\hline Content of extractable ferulic acid & $0.11 \pm 0.03^{\mathrm{a}}$ & $0.30 \pm 0.10^{\mathrm{a}}$ & $1.02 \pm 0.2^{\mathrm{a}}$ \\
\hline Content of nonextractable ferulic acid & $305.1 \pm 68.2^{\mathrm{c}}$ & $102 \pm 26^{\mathrm{b}}$ & $255 \pm 58^{\mathrm{d}}$ \\
\hline \multicolumn{2}{|l}{} \\
\hline
\end{tabular}

